\title{
PROCESSOS DE TRADUÇÃO DA POLÍTICA DE PREVENÇÃO AO BULLYING NA PRÁTICA ESCOLAR
}

\section{TRANSLATION PROCESSES OF THE PREVENTION POLICY OF BULLYING IN THE SCHOOL PRACTICE}

\author{
MARTINS, Ana Carolina Hyer de Faria da Silva ${ }^{1}$ \\ MIRANDA, Edgar ${ }^{2}$ \\ FRIAS, Denise de Medeiros ${ }^{3}$ \\ LIMA, Lucas Pinheiro de
}

\begin{abstract}
RESUMO
A pesquisa analisa duas propostas de trabalho, desenvolvidas no âmbito do Ensino Fundamental I, buscando compreender os mecanismos e artefatos utilizados para tradução da política de prevenção e combate ao bullying na prática escolar. A investigação se orientou analiticamente pela proposta de Ball e colaboradores para compreensão do processo de produção das políticas no contexto da prática. No caso, foram utilizadas como categorias de análise a Interpretação e a Tradução, cujos resultados foram reunidos em duas categorias a posteriori: (i) estratégias e artefatos didático-pedagógicos e (ii) processos de tradução dos elementos de combate e prevenção ao bullying. A título de considerações, reconhecemos que a educação sozinha não transformará o estado de violência da sociedade. Porém, considerase a possibilidade de operacionalização de políticas públicas de prevenção e combate ao bullying nas escolas, a partir da ação criativa dos sujeitos na tradução da política na prática escolar.
\end{abstract}

PaLAVRAS-CHAVE: Prevenção ao bullying, políticas públicas; atuação em política; tradução de políticas; Anos Iniciais.

\section{ABSTRACT}

The research analyzes two work proposals developed in the context of Elementary School, which seek to understand mechanisms and artifacts used to translate the policy of bullying prevention in school practice. The research was analytically oriented by the proposal of Ball and contributors for understanding the process of producing policies in the context of practice. Interpretation and Translation were used as analytical categories. The results were consolidated in two a posteriori categories: (i) didactic-pedagogical strategies and artifacts; (ii) translation processes of the elements for bullying prevention. Lastly, we consider that education alone will not transform society's state of violence. One considers, however, the

\footnotetext{
${ }^{1}$ Colégio Pedro II (CPII). Rio de Janeiro, RJ, Brasil. e-mail: anacarolinahyer@gmail.com

${ }^{2}$ Colégio Pedro II (CPII). Rio de Janeiro, RJ, Brasil. ORCID: https://orcid.org/0000-0003-3736-5532 e-mail: edgar.miranda620@gmail.com

${ }^{3}$ Colégio Pedro II (CPII). Rio de Janeiro, RJ, Brasil. e-mail: deniseufrj@gmail.com

4 Universidade Federal do Rio de Janeiro (UFRJ). Rio de Janeiro, RJ, Brasil. e-mail: lucasbiomedufrj@gmail.com
} 
DOI: $10.12957 /$ e-mosaicos.2020.42098

possibility of operationalization of public bullying prevention policies in schools, based on subjects' creative action in translating politics into school practice.

KEYWORDS: Bullying prevention; public policies; political action; politics translation; Elementary School.

\section{INTRODUÇÃO}

A violência dentro das escolas tem se apresentado como um dos principais problemas da educação (CARVALHO; SILVA, 2011). Impactada pelos reflexos da violência urbana, a escola, hoje, é desafiada a se reconhecer como espaço de produção de violência (OLIVEIRA-MENEGOTTO; PASINI; LEVANDOWSKI, 2013), pois, contraditoriamente ${ }^{5}$, vê aumentar, em seus espaços, casos de violência em suas múltiplas formas: física, psicológica, verbal, sexual, religiosa etc. Nesse sentido, o bullying vem sendo bastante debatido no âmbito escolar, acadêmico e social como uma expressão particular de violência ocorrida na escola.

Esse é um problema educacional complexo que envolve aspectos psicológicos e sociais e que requer ações efetivas de dimensão institucional e política (Ibidem). Após eventos traumáticos de suicídios e morticínios recentes no Brasil, o bullying passou a ser visto como um problema real dentro das instituições escolares do país, devendo ser prevenido e combatido.

Como resposta política à questão, deu-se a criação de leis em vários estados e municípios do país. De modo basilar, essa legislação normatiza o conceito de bullying, suas características e tenta promover ações de prevenção e combate ao problema. Destaca-se nesse âmbito, a Lei Estadual no 6.401/2013 do Rio de Janeiro, promulgada após a ocorrência trágica na Zona Oeste da cidade, na Escola Municipal Tasso da Silveira. Ela estabelece a "Semana de Combate ao bullying e ao cyberbullying" nas escolas públicas da rede estadual do Rio de Janeiro, com a realização de estudos, palestras e outras atividades sobre o tema de forma didática, a fim de promover a conscientização, a prevenção e o combate às práticas violentas de bullying.

Recentemente, o governo federal expediu a Lei no 13.185, de 6 de novembro de 2015, que "institui o Programa de Combate à Intimidação Sistemática (bullying) em todo o território nacional". O programa fundamenta ações do Ministério da Educação e das Secretarias Estaduais e Municipais de Educação, dentre demais órgãos relacionados.

Essa lei amplia o alcance das ações de combate e prevenção aos diversos tipos de violência escolar, com atenção especial ao bullying, determinando que as

\footnotetext{
${ }^{5}$ Consideramos esse fenômeno como contraditório aos fins sociais da escola, os quais compreendemos estarem voltados à socialização dos sujeitos para viver em sociedades democráticas, marcadas pela diferença e multiplicidade de pensamento, gênero, etnia, crença religiosa etc.
} 
DOI: $10.12957 / \mathrm{e}-\mathrm{mosaicos} .2020 .42098$

instituições de ensino desenvolvam medidas de conscientização, prevenção, diagnose e combate à violência e ao bullying. A lei caracteriza intimidação sistemática, quando há violência física ou psicológica em atos de intimidação, humilhação e discriminação, além dos citados abaixo.

Ataques físicos, insultos pessoais, comentários sistemáticos e apelidos pejorativos, ameaças por quaisquer meios, grafites depreciativos, expressões preconceituosas, isolamento social consciente e premeditado, pilhérias, cyberbullying (por meio da internet, depreciar, insultar a violência, adulterar fotos e dados pessoais para criar constrangimento psicossocial). (BRASIL, 2015).

\section{Destarte, especifica bullying como}

todo ato de violência física ou psicológica, intencional e repetitivo que ocorre sem motivação evidente, praticado por indivíduo ou grupo, contra uma ou mais pessoas, com o objetivo de intimidá-la ou agredila, causando dor e angústia à vítima, em uma relação de desequilíbrio de poder entre as partes envolvidas. (BRASIL, 2015).

Dessa forma, caracteriza o bullying em oito tipologias, a saber: verbal, moral, sexual, social, psicológico, físico, material e virtual.

Considera-se a promulgação dessa lei como significativamente importante, tendo em vista a abrangência nacional de suas medidas e seu caráter globalizante que parametriza a noção de bullying e propõe ações para prevenir e combatê-lo em toda a sociedade. Além disso, entende-se que, embora tardia, essa legislação representa um grande avanço político e de sofisticação para área, com a previsão de tratamento não só dos alvos de bullying, mas também dos agressores, por entender que o praticante pode ser uma vítima potencial de outras circunstâncias sociais, econômicas e familiares.

Entretanto, apesar dos esforços estatais de garantir em lei medidas que assegurem o combate e a prevenção do bullying nas escolas, entendemos que, enquanto política pública, as ações propostas pela legislação não serão simplesmente "implementadas" no contexto escolar. Compreendemos a partir de Ball, Maguire e Braun (2012) que, a política, para ser operacionalizada na prática, passa por processos de interpretação institucional e individual, a partir dos quais é (re)criada ou ressignificada conforme a história, as experiências, os valores, os propósitos e os interesses dos sujeitos. Ou seja, para ter atuação, a política de prevenção e combate ao bullying nas escolas depende dos processos criativos dos sujeitos de construção da vivência da política nas escolas (BALL; MAGUIRE; BRAUN, 2012). Entretanto, ainda há 
DOI: $10.12957 /$ e-mosaicos.2020.42098

uma lacuna de conhecimento sobre as estratégias mobilizadas pelos educadores para intervir nas situações de violência na escola (PEQUENO DA SILVA et al, 2019; TOGNETTA; VINHA, 2010), representando um limite do campo de estudo sobre bullying (GONÇALVES; CARDOSO; ARGIMON, 2019).

Nessa perspectiva, o trabalho analisa duas propostas desenvolvidas no âmbito de um projeto de extensão universitária nos Anos Iniciais do Ensino Fundamental, buscando compreender os mecanismos e artefatos utilizados para tradução da política de prevenção e combate ao bullying na prática escolar. Como forma de organização dos resultados da investigação, apresentamos a seguir os elementos teóricos da noção de bullying e que fundamentam nossa visão nas análises. Após, destacamos nossa perspectiva teórico-analítica de políticas públicas e os procedimentos da investigação. Em seguida, discutimos os principais resultados da análise e, por fim, realizamos nossas considerações finais.

\section{BULLYING: ELEMENTOS CONCEITUAIS}

O conceito bullying tem origem inglesa, sendo utilizado para explicar casos específicos de violência escolar. Segundo Esteves (2015), é um termo polissêmico que, para sua compreensão, é necessário entender a caracterização de suas práticas e quais suas possíveis causas e consequências para a dinâmica escolar.

O crescimento da violência nas escolas, após a década de 1990, impulsionou um número expressivo de pesquisas internacionais e nacionais sobre o tema, as quais têm aprofundado o conceito e especificado os elementos de sua dinâmica na escola. Sua definição mais clássica, elaborada por Olweus (1978), diferencia o bullying de outras formas de violência na escola, tais como brincadeiras agressivas. De acordo com o autor, o bullying caracteriza-se por (i) ações repetitivas contra a mesma vítima; (ii) agressões em um período prolongado de tempo; (iii) desequilíbrio de poder entre o agressor e a vítima que não consegue se defender; (iv) ausência aparente de motivos que justificam os ataques; (v) atos de violência ocorridos entre pares.

Outras pesquisas, como a da Organização Não-Governamental (ONG) ABRAPIA (2002 apud LOPES NETO, 2005), buscaram aprofundar essa conceituação classificando os tipos de bullying e os papéis assumidos pelos sujeitos envolvidos nas práticas de bullying. De uma forma geral, autores nacionais e internacionais concordam com a conceituação de bullying definida por atitudes cruéis que utilizam diversos tipos de agressão (física, psicológica, simbólica, verbal, material etc.) (ANTUNES, 2010; ESTEVES, 2015; FANTE, 2005; LOPES NETO, 2005; LOPES NETO \& SAAVEDRA, 2003; OLWEUS, 1978,1993; RIBEIRO, 2014). Porém, consideram que, para a ação violenta ser configurada como bullying, é necessário que as agressões ocorram entre pares; e no caso específico da instituição escolar, entre os(as) educandos(as) e de forma sistemática e constante, em uma relação desigual de poder entre quem o pratica (superior, no comando) e o alvo (inferior, que não consegue sair ou se defender da 
DOI: $10.12957 /$ e-mosaicos.2020.42098

situação de vítima). Além disso, mesmo considerando que o bullying não apresenta motivação aparente, concordam que, em muitos casos, a ação se dá por preconceito e intolerância às diferenças (ANTUNES, 2010; ANTUNES \& ZUIN, 2008).

O bullying pode ser categorizado de diversas formas, tendo, além da tipologia já apresentada (verbal, moral, sexual, social, psicológico, físico e material), outras especificações, como: bullying direto (representa práticas de agressão de um(a) ou mais estudantes que atacam diretamente $\mathrm{a}(\mathrm{s})$ vítima(s)); e bullying indireto (caracterizado por atitudes menos aparentes, como, por exemplo, quando um(a) aluno(a) é tratado(a) com indiferença por seus pares, ou é isolado(a) (LOPES NETO, 2005). A violência envolvida nesse processo é simbólica e/ou psicológica) (LOPES NETO, 2005; OLWEUS, 1993; FANTE, 2005). No âmbito virtual é considerado como cyberbullying ou bullying digital, que ocorre quando as agressões são realizadas por meio da internet, principalmente, nas redes sociais. (LOPES NETO, 2005).

Outro elemento relevante nas situações de bullying são os papéis assumidos pelos indivíduos nessas ações. Comumente, são identificados os seguintes participantes: praticantes dos atos de violência, os que sofrem com a violência e os que não praticam nem sofrem, mas estão observando, testemunhando, incentivando ou apenas ignorando as ações de violência (MARTINS, 2016).

Segundo Lopes Neto (2005), a ONG ABRAPIA destaca a seguinte tipologia: alvos de bullying, autores de bullying, testemunhas e alvos-autores. Os alvos de bullying são os indivíduos expostos às agressões de todo o tipo (verbal, simbólica e psicológica). As vítimas não manifestam reação de enfrentamento, seja por meio de solicitação de ajuda a outros indivíduos, ou por meio de revide aos autores das agressões sofridas. Os autores de bullying são os que agridem. Seu perfil antissocial é determinado por diversos fatores, como, por exemplo, o relacionamento familiar.

Quanto às testemunhas, são os indivíduos que tomam ciência do bullying, mas não praticam ou sofrem com suas práticas. Eles podem se colocar no papel de observadores, auxiliares ou defensores. De acordo com Lopes Neto (2005), os alvosautores representam $20 \%$ da parcela dos autores de bullying que também são vítimas dessa prática.

Por fim, é importante ressaltar a mobilidade desses papéis, existindo situações em que a vítima se torna agressor. Esse fato caracteriza o bullying, suas ações, motivação e os sujeitos envolvidos como um fenômeno dinâmico e complexo, não podendo ser tratado como algo natural (MARTINS, 2016).

\section{Perspectiva teórico-Analítica e PROCedimentos da Pesquisa}

A proposta teórico-analítica da "Sociologia das políticas públicas" situa as políticas educacionais como um produto social, resultante de "uma combinação" complexa "de forças políticas, estruturas sociais, tradições culturais e processos 
econômicos" que são envolvidos em redes de ideias e discursos de "intersecção multinível" e "multi-escalar" (VERGER; NOVELLI; ALTINYELKEN, 2018, p.7). Nessa perspectiva, seu processo de produção é entendido como um território disputado, em que visões de mundo estarão em disputa buscando influenciar os sentidos da política de forma a interferir e regular a realidade conforme seus interesses.

Além disso, a ideia de implementação, como processo verticalizado de execução de fins e ações específicos, é contestada, na medida em que se considera que a operacionalização das políticas educacionais se dá de forma mediada com os contextos de sua atuação (BALL, 2011; BALL; MAGUIRE; BRAUN, 2012). Ou seja, os discursos e propostas políticas precisam dialogar com a realidade, a partir de seus elementos estruturais, físicos, históricos, culturais, econômicos e sociais. Isso, porque, concebese a escola como um espaço autônomo de "produção de significados" próprios (LOPES; MACEDO, 2011, p.165), estando, a tentativa de construção dos discursos pedagógicos voltados à atuação da política na prática, sujeita a processo de leitura e interpretação da instituição e dos sujeitos que nela atuam, podendo haver adoção, assimilação de partes ou rejeição dos discursos da política.

Com base nesse pressuposto, entende-se que a (re)construção da política de prevenção e combate ao bullying nas escolas passa pela atuação criativa (enactment) de interpretação e tradução dos sujeitos para ser vivida de formas diferentes e variadas no espaço escolar (BALL; MAGUIRE; BRAUN, 2012).

Nesse sentido, a presente pesquisa buscou compreender os mecanismos e artefatos utilizados por servidores de uma escola federal de Educação Básica e graduandos de Biomedicina para tradução da política de prevenção e combate ao bullying na prática escolar. Para acessar esses elementos foram analisadas duas propostas de trabalho, elaboradas no âmbito de um projeto de extensão universitária nos Anos Iniciais do Ensino Fundamental, por meio de uma investigação-ação, em que professores, pesquisadores e graduandos, sob a lógica reflexão-ação-avaliação, buscaram construir projetos de melhoria da educação pública. O processo de reflexão indicou a falta de estratégias para combater o bullying como um problema enfrentado pela escola, sendo este selecionado como tema de trabalho. Das discussões realizadas sobre 0 assunto surgiram duas propostas de ação.

A primeira proposta consistiu no Projeto "Diga não ao Bullying", o qual foi desenvolvido por professores em uma turma de $3^{\circ}$ ano do Ensino Fundamental por meio de uma sequência didática que tinha como objetivo principal a sensibilização dos alunos para situações de bullying relacional que estavam ocorrendo no grupo. Enquanto a segunda foi elaborada por graduandos de Biomedicina da UFRJ, participantes das atividades extensionistas de uma disciplina eletiva - "Ciência, Tecnologia e Sociedade na Educação" - oferecida pelo Instituto NUTES - UFRJ. Em colaboração com professores da escola, os graduandos desenvolveram um jogo de trilha com o objetivo principal de promover a saúde mental dos alunos a partir da construção de ações de combate ao bullying nas escolas. 
DOI: $10.12957 /$ e-mosaicos.2020.42098

Essas propostas foram analisadas a partir das categorias analíticas apresentadas por Ball para compreensão dos processos de tradução da política, a saber: Interpretação e Tradução. A Interpretação é entendida como a (de)codificação do texto a partir dos elementos culturais e históricos do contexto institucional: "é um processo político institucional, uma estratégia, 'uma cadeia de gênero' (recontextualização), um processo de explicação, esclarecimento e a criação de um compromisso institucional, 'muitas vezes contraditório e sempre socialmente instituídos'" (BALL; MAGUIRE; BRAUN, 2012, p. 45, aspas dos autores). Já o processo de Tradução está relacionado com a política em ação, para qual são mobilizadas táticas, estratégias e artefatos variados, como planos, eventos, cursos de formação, produção e aquisição de materiais, empréstimo de ideias e práticas de outras escolas etc. (Ibidem). "É um processo interativo de construção de textos e ações institucionais" (MIRANDA; FERNANDES; VIEIRA; OLIVEIRA; VILANOVA, 2018, p. 252).

Os dados foram reunidos em categorias temáticas a posteriori, as quais são apresentadas na próxima seção.

\section{RESULTADOS E DISCUSSÕES}

Como dito, os resultados das análises foram reunidos em duas categorias temáticas, a saber: (i) estratégias e artefatos didático-pedagógicos e (ii) processos de tradução dos elementos de combate e prevenção ao bullying. Estas categorias são apresentadas com mais especificidades a seguir.

\section{(i) estratégias e artefatos didático-pedagógicos}

Como mencionado, as propostas de operacionalização da política de combate e prevenção ao bullying foram desenvolvidas por meio de estratégias didáticas diferentes, sendo a primeira organizada a partir de uma sequência didática e a segunda, por um jogo de trilha.

A sequência didática (SD) tem sido uma estratégia significativa de planejamento do ensino. Caracteristicamente, é entendida como um conjunto de ações sequenciadas, progressivas e interligadas por um tema ou meta comum. Potencialmente, possibilita aos docentes uma forma de organização gradual e ascendente dos conteúdos, respeitando e organizando a construção dos conhecimentos pelos alunos. No caso, a SD proposta teve como elemento disparador das discussões a "A história de Zequinha", que narrava, ficticiamente, a transferência e adaptação de um aluno para sua nova escola, a qual foi marcada por atitudes de bullying verbal e social por parte dos colegas da nova turma. A narrativa buscou desnaturalizar a situação a partir de questionamentos geradores do debate, tendo como questão norteadora: "Vocês sabem o que acontece com uma pessoa que é tratada desse jeito?". 
DOI: $10.12957 /$ e-mosaicos.2020.42098

Como forma de sensibilização dos alunos para o problema, foi utilizada a dinâmica "o papel amassado", em que os alunos amassavam uma folha de papel e, entrementes, citavam o que poderia estar sendo dito ao Zequinha para o entristecer. A atenção aos vincos formados na folha buscou construir uma analogia com os sentimentos que iam sendo gerados no personagem. $E$, por mais tentativas que se fizessem para desamassar a folha, os alunos não conseguiam reverter o processo, sendo destacado pelo grupo que apenas desculpas não seriam suficientes para contornar as ações de bullying, sendo ressaltados os possíveis problemas psicológicos e sociais que poderiam decorrer dessa situação.

Para discussão desses elementos foram realizadas "rodas de conversa", tendo como produto dos debates, a construção de um cartaz coletivo de publicização e denúncia da situação do Zequinha, como pode ser observado abaixo:

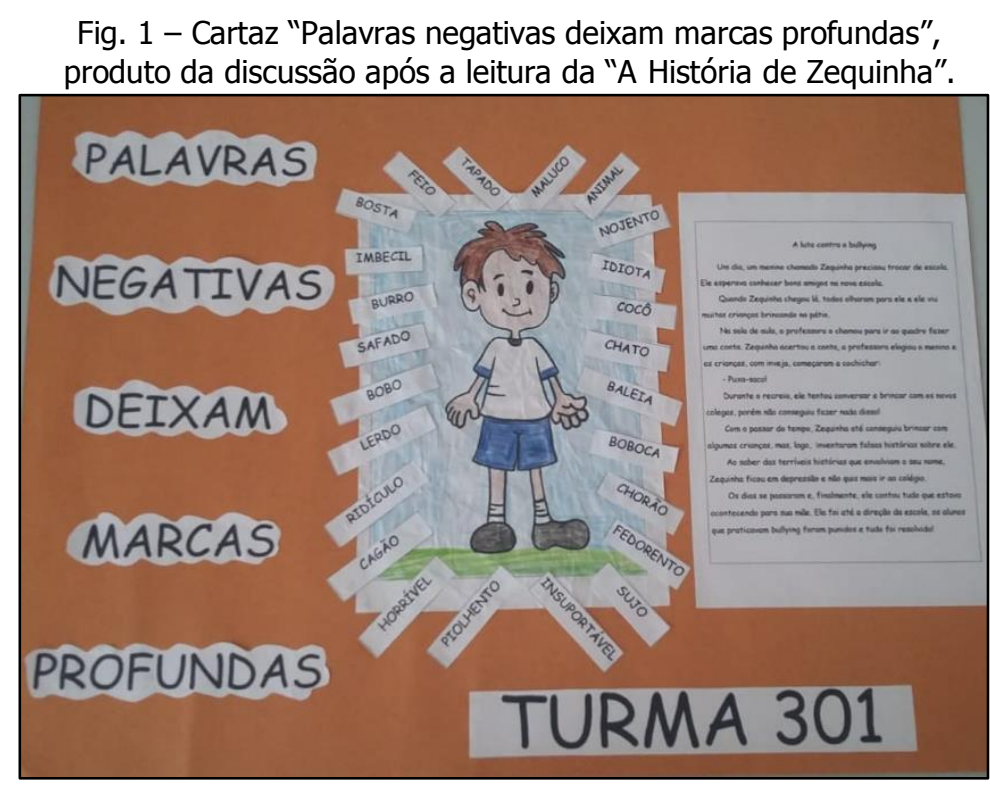

Em um segundo momento, foram apresentados ao grupo 20 títulos da Coleção Bullying na Escola, da Blu Editora, com textos escritos por Cristina Klein, com ilustrações de Solange Janette Passos Reetz, que buscou identificar situações que se caracterizavam como bullying e traçar estratégias de combate. Durante, aproximadamente, 2 meses, ao final de cada aula um estudante era sorteado e o mesmo escolhia o livro a ser lido pela professora e as situações de bullying eram discutidas com o grupo.

Como forma de sistematização dos conhecimentos, "o Jogo antibullying", que será apresentado a seguir, foi realizado com a turma, sendo esta uma oportunidade de aplicação e ampliação dos conhecimentos. Por fim, como forma de ativismo e de multiplicação da proposta para outros grupos, os alunos, em grupos, confeccionaram cartazes abordando o tema 'bullying e os apresentaram para as turmas do primeiro ao quinto ano. Durante as apresentações foram gerados novos debates com os demais 
estudantes. Os cartazes confeccionados ficaram expostos nos corredores do colégio, até o fim do ano letivo de 2017.

Quanto à proposta do Jogo de trilha, como dito, foi pensada no âmbito de uma parceria universidade escola, a qual buscou promover a saúde mental dos alunos a partir da construção de ações de combate ao bullying nas escolas. Sua elaboração se deu de forma colaborativa, sendo o projeto elaborado por alunos do curso de Biomedicina da UFRJ e validado por professores da Educação Básica, que apontaram questões sobre a operacionalidade e adequação do jogo à faixa etária dos alunos. Posteriormente, o jogo foi realizado diretamente com alunos de dois campi de um colégio federal, em turmas de $3^{\circ}, 4^{\circ}$ e $5^{\circ}$ anos do Ensino Fundamental, tendo uma recepção positiva por parte dos alunos e professores.

A opção pelo jogo, como artefato de operacionalização da política, levou em consideração a possibilidade de vivências lúdicas, as quais entende-se que permitem um processamento associativo e raciocínio mais rico, rápido e criativo, "com uma maior variedade de indícios" e um modo cognitivo mais ativo, com a realização de inferências (DAMÁSIO, 1996, p.195). Além disso, jogos e brincadeiras cooperativos vêm sendo apontados como estratégia importante no combate e prevenção ao bullying (BARROS; CARVALHO; PEREIRA, 2009; BARROS, 2012).

No caso, foram manufaturadas duas versões do jogo, uma em tamanho de tabuleiro de mesa e outra ampliada para atender grupos maiores de alunos e para permitir que eles atuassem como peões. Ambas as versões possuem seis peões, 50 cartas e um tabuleiro com 32 casas que, no modo ampliado, podem ser (re)distribuídas conforme as circunstâncias de tempo, espaço e do grupo. As casas do tabuleiro apresentam seis situações distintas, a saber: Desafio, Atitude, Bônus, (Cyber) Bullying e "Bullying não é brincadeira". Essas casas têm correspondência com as cartas do jogo. Quando um jogador cai na casa "Desafio", é obrigado a retirar uma carta "Desafio", na qual constam perguntas sobre situações de bullying e suas caracterizações possíveis. Ao cair na casa "Atitude", é apresentada ao aluno, ou ao grupo de alunos, uma possível situação de bullying em que o mesmo deverá identificar o tipo de bullying praticado e propor ações que possam evitar ou combater as atitudes de violência. Na casa "Bônus", o jogador é bonificado por supostamente ter realizado alguma ação antibullying. Enquanto na casa "(Cyber)Bullying" o jogador é penalizado por ter cometido uma ação de (Cyber) Bullying. Por fim, ao cair na casa "Bullying não é brincadeira", todos os alunos envolvidos no jogo devem falar a frase que nomeia a casa em voz alta.

Com base em Ball, Maguire e Braun (2012), considera-se essas propostas, sequência didática e o jogo de trilha, como formas de materialização da política na prática escolar. Estes seriam artefatos, elementos ou instrumentos (in)materiais que trabalham para estabelecer e manter a atuação da política no contexto escolar. Muitos desses "artefatos e práticas são fundamentais para a coprodução de atividades escolares de políticas" (Ibidem, p. 136), sendo que muitas políticas têm existência 
DOI: $10.12957 /$ e-mosaicos.2020.42098

devido à criação desses artefatos pela escola. Essas propostas têm relevância na efetivação das políticas de bullying por atuarem em um campo complexo, qual seja a mudança de comportamentos, educação em valores éticos e na construção de laços afetivos (SANCHÉZ, 2013).

Entretanto, nesse contexto de atuação em dimensões axiológicas, por meio da promoção de valores e sentimentos que orientam o comportamento, a utilização desses artefatos apresenta limites, pois as ações necessitam de sustentabilidade, mantendo uma constância e precisando serem assumidas institucionalmente, para que a atuação da política não se dê de forma estanque ou esporádica. O tempo de duração foi apontado na revisão de Gonçalves, Cardoso e Argimon (2019) como um elemento importante na eficácia das ações de combate e intervenção relatadas pelas pesquisas da área.

No caso, é necessário o compromisso institucional por meio da garantia de ações no Projeto Político Pedagógico e nos currículos, possibilitando atividades na escola que valorizem as diferenças culturais e sociais, a tolerância ao outro, o indivíduo como ser social e participativo na comunidade; projetos de formação sobre o tema com professores(as), equipe técnica, equipe pedagógica e as famílias; criação de espaços de escuta e diálogo entre alunos, profissionais e as famílias; grupos de mediação de conflitos e ações imediatas e coercitivas contra as práticas de bullying detectadas (MARTINS, 2016). Dessa forma, é possível que as ações estejam além de uma "implementação performativa", em que a escola elabora uma resposta ou presta contas à política mencionando-a em seus documentos, mas sem efetividade ou influência nas práticas pedagógicas ou nos espaços escolares (BALL; MAGUIRE; BRAUN, 2012).

\section{(ii) processos de tradução dos elementos de combate e prevenção ao bullying}

Como destacamos, a identificação e, principalmente, a caracterização das situações de bullying e a construção de ações de prevenção e combate são complexas, quase sempre, não são contempladas ou previstas nas políticas e práticas escolares, gerando a necessidade de mecanismos que possam operacionalizar esses elementos de forma efetiva e criando uma "lacuna de conhecimento nesse campo" (PEQUENO DA SILVA et al., 2019; TOGNETTA; VINHA, 2010; GONÇALVES; CARDOSO; ARGIMON, 2019). Nesse caso, buscamos analisar os mecanismos utilizados pelas propostas apresentadas aqui para tradução de elementos de identificação e caracterização do bullying, processo o qual entendemos envolver aspectos axiológicos como alteridade e empatia.

De forma geral, percebemos que o caminho traçado por ambas as propostas passa pela "desnaturalização" das situações de violência escolar e pela identificação de suas múltiplas formas. A problematização das situações de bullying é apresentada nas propostas como mecanismo de viabilização desse processo. No caso da sequência didática, a dinâmica do "papel amassado" é utilizada como elemento disparador para 
DOI: $10.12957 /$ e-mosaicos. 2020.42098

as discussões e sensibilização dos estudantes sobre a situação de violência que o novo aluno vem enfrentando. Essa reflexão dos alunos é expressa no cartaz confeccionado pela turma e que narra a história do personagem: "Ao saber das terríveis histórias que envolviam o seu nome, Zequinha ficou em depressão e não quis mais ir ao colégio".

A identificação dos sentimentos da vítima coloca-se, nesse caso, como um princípio de sensibilização e empatia com o outro. A promoção de sentimentos como empatia e valores sociais relacionados a uma cultura de paz é colocada como estratégia de intervenção de vários programas de combate ao bullying identificados por Gonçalves, Cardoso e Argimon (2019). No caso das propostas aqui analisadas, esse objetivo passa pelo processo de problematização, que é expandido com as ações posteriores da SD, a partir das quais novos elementos, como os tipos de bullying, vão sendo discutidos, ampliando a noção de violência em seus aspectos verbais, psicológicos, físicos etc.

No caso do jogo de trilha, as cartas e casas atitudes ganham destaque por ressaltarem situações que precisam ser problematizadas e analisadas pelos alunos, os quais devem identificar possíveis situações de bullying, como é demonstrado na Figura 2.

Fig. 2 - Exemplo de carta "atitude" utilizada no jogo de trilha sobre bullying.

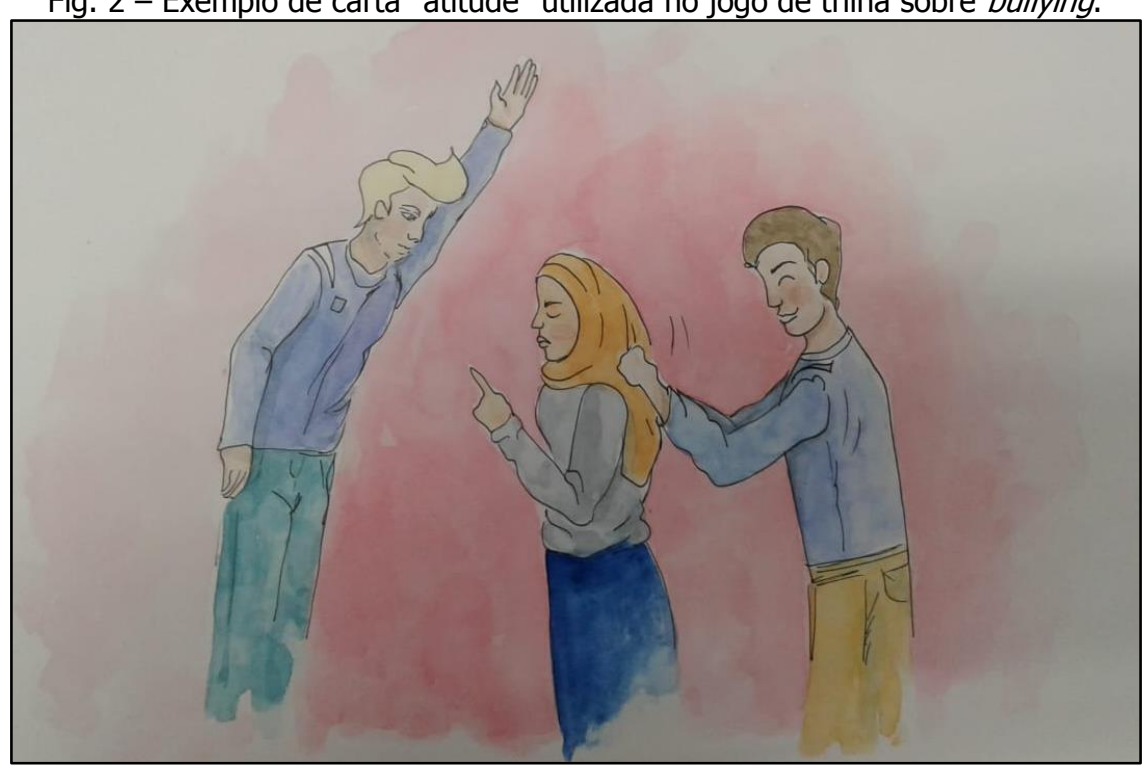

Esse processo de problematização impele os participantes do jogo a analisar as situações apresentadas a partir da perspectiva dos sujeitos alvo da violência, avaliando, por exemplo, quando as ocorrências se tratam de bullying de caráter físico, religioso, étnico-racial, sexual, entre outros. Além disso, o jogador deverá apresentar propostas de solução imediatas ou duradouras para resolução do problema, o que entendemos ser um processo ainda mais complexo de análise e trabalho das 
DOI: $10.12957 /$ e-mosaicos.2020.42098

circunstâncias envolvidas e que considera os alunos como agentes de intervenção. De acordo com Gonçalves, Cardoso e Argimon (2019), são poucas as propostas de intervenção em que os alunos atuam como mediadores de conflitos.

No caso do jogo, a problematização aparece como um processo/método que descortina a realidade, desnaturalizando e desvelando os aspectos contextuais das situações e possibilitando a articulação de elementos axiológicos tendentes à socialização pacífica e respeitosa com o outro, com o desenvolvimento de estados de empatia e alteridade.

Quanto à caracterização dos tipos de bullying, na sequência didática foram utilizados textos literários. Esse gênero tem uso consolidado na educação como instrumento didático importante para o desenvolvimento integral da criança, por abordar outras dimensões da realidade, como a social, política e econômica. Pela capacidade imaginativa e inventiva possibilita a crítica para atuação consciente na sociedade a partir de atitudes éticas. No caso, as narrativas, sobretudo de cunho moral, como na proposta apresentada, se propõem a desenvolver processos de reflexão da realidade, estimulando a (re)leitura do mundo a partir de sua complexidade contextual, social e ética.

A problematização a partir de debates e narrativas de cunho morais são alguns dos mecanismos de sensibilização para a questão, em que os questionamentos gerados permitem ampliar as discussões e articular elementos da política, como tipos de bullying e estratégias de prevenção e enfrentamento, na prática. Percebe-se que é por meio desse processo de questionamento das situações, que os professores conseguem articular temas mais agudos e de dimensões éticas. Instrumentos que envolvem a discussão de grupos, como trabalhos em grupo e exercícios do tipo roleplaying, têm sido apontados positivamente para redução da vitimização dos alunos (WILLIFORD et al., 2012).

\section{CONSIDERAÇÕES FINAIS}

A título de considerações finais, reconhecemos que a educação sozinha não transformará o estado de violência da sociedade, pois esse problema envolve dimensões mais complexas, amplas e externas à escola. Porém, atualmente, não se pode negar a violência produzida no espaço escolar e que precisa ser enfrentada em seus diversos aspectos. Isso inclui a (re)construção de valores e comportamentos éticos e de respeito à diferença como contribuição da escola à criação de uma sociedade justa e igualitária.

Orientados por essa perspectiva, consideramos a possibilidade de operacionalização de políticas públicas de prevenção e combate ao bullying nas escolas, apostando na ação criativa dos sujeitos em traduzir elementos importantes 
DOI: $10.12957 /$ e-mosaicos.2020.42098

dessa política na prática escolar. Nesse sentido, os resultados da pesquisa apontam estratégias e artefatos didático-pedagógicos utilizados por profissionais da educação para colocar a política em ação. No caso, é destacado o uso de sequências didáticas, jogos, dinâmicas, rodas de conversa, textos, livros literários, entre outros recursos didáticos. Enfatizamos que esses seriam possíveis instrumentos (in)materiais que trabalham para estabelecer e manter a atuação da política no contexto escolar.

Da mesma forma, consideramos a necessidade de estabelecer compromissos e ações institucionais que deem sustentabilidade e efetivação a práticas de prevenção e combate ao bullying na escola.

Um possível caminho apontado pelos resultados da pesquisa passa pela promoção de aspectos axiológicos como alteridade e empatia, os quais são trabalhados a partir da "desnaturalização" das situações de violência escolar. No caso, as análises apontam a problematização das situações de bullying como mecanismo de viabilização desse processo, na medida em que envolve os alunos na discussão de situações dos sujeitos alvo desse tipo violência escolar. Esse parece ser um processo/método que descortina a realidade, desnaturalizando e desvelando os aspectos contextuais das situações e possibilitando a socialização pacífica e respeitosa com o outro e o desenvolvimento de estados de empatia e alteridade.

Entretanto, não se pode abordar essas indicações como panaceia. O problema do bullying na escola não tem resolução simples, sendo necessário entendê-lo dentro de uma conjuntura social, cultural, política e econômica que é condicionante dessa situação de violência. Portanto, é necessária uma análise crítica sobre o que realmente o bullying representa na sociedade e na escola.

\section{REFERÊNCIAS}

ANTUNES, D. C. Bullying: razão instrumental e preconceito. São Paulo: Casa do Psicólogo, 2010.

ANTUNES, D. C. \& ZUIN, A. A. S. Do bullying ao preconceito: os desafios da barbárie à educação. Revista Psicologia e Sociedade. v. 20, n. 1. Porto Alegre. Jan/Abril, 2008.

BALL, S. J. Sociologia das políticas educacionais e pesquisas crítico-social: uma revisão pessoal das políticas educacionais e da pesquisa em política educacional. In: BALL, S.; MAINARDES, J. (Org.). Políticas Educacionais. questões e dilemas. São Paulo: Cortez, 2011. 
DOI: $10.12957 /$ e-mosaicos.2020.42098

BALL, S. J.; MAGUIRE, M; BRAUN, A. How Schools do Policy: Policy Enactments in Secondary Schools. New York: Routledge, 2012.

BARROS, J. E.; CARVALHO, P. C.; PEREIRA, M. B. F. L. O. O lúdico como uma possibilidade de intervenção ao bullying e formação da criança na escola. In: Anais do IX Congresso Nacional de Educação - EDUCERE/ III Encontro Sul Brasileiro de Psicopedagogia. De 26 a 29 de outubro de 2009.

BARROS, P. L. Jogos e Brincadeiras na Escola: Prevenção do bullying entre crianças no Recreio. 217 p. Tese (Doutorado em Estudos da Criança, Conhecimento em Educação Física, Lazer e Recreação) - Universidade do Minho, Instituto de Educação. 2012

BRASIL. Presidência da República. Lei n 13.185 de 6 de novembro de 2015. Institui o Programa de Combate à Intimidação Sistemática (Bullying). Brasília, 2015.

BRASIL. Governo do Estado do Rio de Janeiro. Lei estadual n 6401/13 de 5 de março de 2013 - a Semana de Combate ao Bullying e ao Ciberbullying nas escolas públicas e privadas do Estado do Rio de Janeiro. Rio de Janeiro, 2013.

CARVALHO, A. A. L; SILVA, M. L. O bullying e a gestão democrática de escolas públicas: algumas reflexões. In: Olhares Plurais - Revista Eletrônica Multidisciplinar, v. 1, n. 4, 2011.

DAMASIO, A. R. O erro de Descartes: emoção, razão e o cérebro humano. São Paulo: Companhia das Letras, 1996.

ESTEVES, P. S. da M. A escola não é um lugar fácil...não mesmo!: bullying, nãoreconhecimento da diferença e banalidade do mal. Tese de doutorado em educação - PUC do Rio de Janeiro, Rio de Janeiro, 2015.

FANTE, C. Fenômeno bullying: como prevenir a violência nas escolas e educar para paz. 2. ed. Campinas: Versus, 2005.

GONÇALVES, F. V.; CARDOSO, N. O.; ARGIMON, I. I. L. Estratégias de intervenção para adolescentes em situações de bullying escolar: uma revisão sistemática. In: Contextos clínicos, v. 12, n. 2, 2019.

LOPES NETO, A. A. Bullying - comportamento agressivo entre estudantes. In: Jornal de Pediatria. Rio de Janeiro, v. 81, n.5, 2005.

LOPES NETO, A. A. \& SAAVEDRA, L. H. Diga não para o bullying - Programa de redução do comportamento agressivo entre estudantes. Rio de Janeiro. ABRAPIA, 2003. 
DOI: $10.12957 /$ e-mosaicos.2020.42098

LOPES, A. C.; MACEDO, E. Contribuições de Stephen Ball para o estudo de políticas de currículo. In: BALL, S.; MAINARDES, J. (Org.). Políticas Educacionais: questões e dilemas. São Paulo: Cortez, 2011.

MARTINS, A. C. H. de F. da S. "Nem sempre o adulto resolve...": o serviço de orientação educacional e as práticas de bullying no primeiro segmento do ensino fundamental. Dissertação de mestrado - Instituto de Aplicação Fernando Rodrigues da Silveira -CAp UERJ, Rio de Janeiro, 2016.

MIRANDA, E.; FERNANDES, L.; VIERA, C.; OLIVEIRA, G.; VILANOVA, R. Currículo e resistência: ressignificação curricular a partir da educação científica crítica. In: MIRANDA, E.; FERREIRA, A. [et al] (Org.). Atuação docente em políticas educacionais: processos de ressignificação da política no cotidiano escolar. Rio de Janeiro: Imperial, 2018.

OLIVEIRA-MENEGOTTO, L. M.; PASINI, A. I.; LEVANDOWSKI, G. O bullying escolar no Brasil: uma revisão de artigos científicos Psicologia. In: Teoria e Prática, v. 15, n. 2, 2013.

OLWEUS, D. Aggression in schools. Bullies and whipping boys. Washington D.C.: Hemisphere, 1978.

. Bullying at school: what we know and what we can do. United Kingdom: Blackwel publishing, 1993.

PEQUENO DA SILVA, G.; SILVA, G. P.; FERNANDES, R. M.; MORIEL JUNIOR, J. G. Bullying e violência no ambiente escolar: uma revisão de literatura no período de 2015-2019. Revista Eletrônica Acervo Saúde, v. 11, n. 13, 2019.

RIBEIRO, W. DE G. Multiculturalismo e ética/moral em educação; a retórica no discurso contra o bullying. Tese de doutorado programa de pós-graduação UFRJ. Rio de janeiro, 2014.

SANCHEZ, R. Y. Intervención educativa para resolver un caso de acoso escolar. Psicologia Escolar e Educacional, v. 17, n. 2, 2013.

TOGNETTA, L. R. P.; VINHA, T. P. Até quando? Bullying na escola que prega a inclusão social. In: Educação, Santa Maria, v. 35, n. 3, 2010.

VERGER, A.; NOVELLI, M.; ALTINYELKEN, H. K. Global Education Policy and International Development: a revisited introduction. In: VERGER, A.; NOVELLI, M.; ALTINYELKEN, H. K. Global Education Policy and International Development. new agendas, issues and policies. $2^{\mathrm{a}}$ ed. London: Bloomsbury, 2018. 
DOI: $10.12957 / \mathrm{e}-\mathrm{mosaicos} .2020 .42098$

WILLIFORD, A; BOULTON, A.; NOLAND, B. LITTLE, T. D. KARNA, A; SALMIVALLI, C. Effects of the KiV a anti-bullying program on adolescents depression, anxiety, and perception of peers. In: Journal of Abnormal Child Psychology, v. 40, n. 2, 2012.

A e-Mosaicos Revista Multidisciplinar de Ensino, Pesquisa, Extensão e Cultura do Instituto de Aplicação Fernando Rodrigues da Silveira (CAp-UERJ) está licenciada com uma Licença Creative Commons - Atribuição-NãoComercial 4.0 Internacional.

Os direitos autorais de todos os trabalhos publicados na revista pertencem ao(s) seu(s) autor(es) e coautor(es), com o direito de primeira publicação cedido à e-Mosaicos.

Os artigos publicados são de acesso público, de uso gratuito, com atribuição de autoria obrigatória, para aplicações de finalidade educacional e não-comercial, de acordo com o modelo de licenciamento Creative Commons adotado pela revista. 